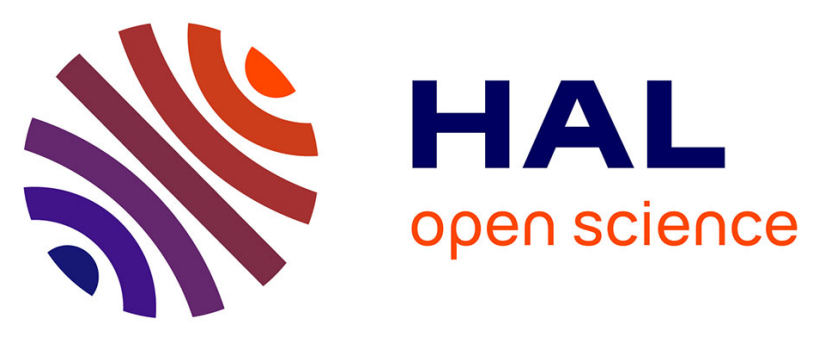

\title{
Concentration of ions in the topside ionosphere as measured onboard the DEMETER satellite: Morphology and dependence on solar and geomagnetic activity
}

\author{
V. A. Gladyshev, A. Yu. Shchekotov, N. V. Yagova, Jean-Jacques Berthelier, \\ Michel Parrot, O. S. Akent'Eva, L. N. Baranskii, E. N. Fedorov, T. M. \\ Mulyarchik, O. A. Molchanov
}

\section{To cite this version:}

V. A. Gladyshev, A. Yu. Shchekotov, N. V. Yagova, Jean-Jacques Berthelier, Michel Parrot, et al.. Concentration of ions in the topside ionosphere as measured onboard the DEMETER satellite: Morphology and dependence on solar and geomagnetic activity. Cosmic Research / Kosmicheskie Issledovaniya, 2012, 50 (2), pp.103-115. 10.1134/S0010952512020037 . hal-00693328

\section{HAL Id: hal-00693328 https://hal.science/hal-00693328}

Submitted on 12 Mar 2015

HAL is a multi-disciplinary open access archive for the deposit and dissemination of scientific research documents, whether they are published or not. The documents may come from teaching and research institutions in France or abroad, or from public or private research centers.
L'archive ouverte pluridisciplinaire HAL, est destinée au dépôt et à la diffusion de documents scientifiques de niveau recherche, publiés ou non, émanant des établissements d'enseignement et de recherche français ou étrangers, des laboratoires publics ou privés. 


\title{
Concentration of Ions in the Topside Ionosphere as Measured onboard the DEMETER Satellite: Morphology and Dependence on Solar and Geomagnetic Activity
}

\author{
V. A. Gladyshev' ${ }^{1,2}$, A. Yu. Shchekotov' 1 , N. V. Yagova ${ }^{1}$, J.-J. Berthelier ${ }^{3}$, M. Parrot ${ }^{4}$, \\ O. S. Akent'eva ${ }^{2}$, L. N. Baranskii ${ }^{1}$, E. N. Fedorov ${ }^{1}$ T. M. Mulyarchik ${ }^{2}$, and O. A. Molchanov ${ }^{\dagger 1}$ \\ ${ }^{1}$ Schmidt Institute of Physics of the Earth, Russian Academy of Sciences, ul. Bol'shaya Gruzinskaya 10, \\ Moscow, 123810 Russia \\ ${ }^{2}$ Space Research Institute, Russian Academy of Sciences, ul. Profsoyuznaya 84/32, Moscow, 117997 Russia \\ ${ }^{3}$ CETP/IPSL, 4 Ave de Neptune, 94107, Saint-Maur, France \\ ${ }^{4}$ LPCE/CNRS, $3 A$ Ave de la Recherhe, 45071 Orleans cedex 02, France \\ e-mail: glad@ifz.ru \\ Received March 3, 2011
}

\begin{abstract}
Variations in concentration of ions $\mathrm{H}^{+}, \mathrm{He}^{+}$, and $\mathrm{O}^{+}$are studied at a height of about $700 \mathrm{~km}$ using the data of continuous observations onboard the DEMETER satellite at the decline and in the minimum of solar activity from 2004 to 2008. Latitudinal distributions, seasonal behavior, and irregular variations in ion concentrations and their dependence on solar and geomagnetic activity are considered. Within this altitude range, for the first time an analysis is performed of the dataset of many-year continuous observations in both hemispheres from the equatorial to subauroral latitudes. This made it possible to describe the seasonal and irregular variations of the concentrations of main ion species with better time and spatial resolution than in the available empirical models. The dependence of concentrations of three types of ions on solar and geomagnetic activity is studied at time scales from several days to several years, and it is shown that the anti-phase change in concentrations of $\mathrm{O}^{+}$and light ions known from publications is partly a result of mutual dependence of solar and geomagnetic activity and is observed only at time scales beginning from several months. At time scales from several days to several weeks, variations in the concentration of $\mathrm{O}^{+}$and light ions are governed mainly by solar and geomagnetic activity, respectively.
\end{abstract}

DOI: $10.1134 / \mathrm{S} 0010952512020037$

\section{INTRODUCTION}

The ionospheric plasma above the electron density maximum is intermediate from the ionospheric plasma where heavy ions prevail, first of all, $\mathrm{O}^{+}$, to the plasma typical for the plasmasphere, with domination of protons. At the transition of the oxygen-dominant to proton plasma, properties of the ionosphere change in a substantial way, so the height where the concentrations of $\mathrm{O}^{+}$and light ions $\left(\mathrm{H}^{+}\right.$and $\left.\mathrm{He}^{+}\right)$become equal, called the ionospheric upper transition height, is an important parameter of ionospheric models (see, for example, [1]). The distributions of the thermal plasma density in the topside ionosphere are measured both onboard satellites [2-4] and with the help of radars. Results and constraints of early radar observations are presented in [5]. Depending on the height and inclination of the orbit, satellite measurements in the topside ionosphere provide either a vertical profile within a limited latitudinal and longitudinal range, or measurements almost at one and the same height within a wide range of latitudes. The first conclusions on the composition and main plasma parameters in the topside ion-

\footnotetext{
${ }^{\dagger}$ Deceased
}

osphere were obtained in the early radar measurements [5] and onboard high-apogee satellites [6] which have measured vertical profiles of ion concentrations and established that the ionospheric upper transition height lies at various values of local time, latitude, and solar activity level at heights from 500 to $2000 \mathrm{~km}$. Already in the first publications with analysis of the satellite data [7], the main features of vertical profiles of concentrations of main ion species were obtained, and the dependence of concentrations of heavy ions (direct) and light ions (inverse) on solar and geomagnetic activity was found. The analysis of measurements onboard the $O G O$ series satellites [8] revealed a complicated character of the latitudinal dependence of concentrations in the topside ionosphere and strong longitudinal variation which are governed by a combination of the neutral wind and the $[\mathrm{E} \times \mathbf{B}]$ drift. At low latitudes, the influence of tidal effects is also important [9]. These factors and strong variability of ion concentrations with time and in space lead to difficulties in creation of a reliable empirical model of plasma in the topside ionosphere. For example, even the recent versions of the IRI model [1] differ substantially from the data of mea- 
surements of light ion concentrations in the topside ionosphere, and values of ion concentrations in the topside ionosphere for different models differ severalfold. In a series of publications [10-13], the empirical model TTS (Truhlik, Triskova, Smilauer) for vertical profiles of relative concentrations of the main ion species and their variations in the solar activity cycle was proposed. The transition to absolute values was performed using the data on the total electron content. The model height of the upper ionospheric transition reaches $2000 \mathrm{~km}$ in the conditions of solar activity maximum and lies in the interval from 700 to $1100 \mathrm{~km}$ for solar minimum. The allowance for the seasonal variation is performed by splitting into three seasons centered on the June and December solstices and on equinoxes (without separation of the March and September ones). As a result, the latitudinal distribution of ion concentrations in the equinoxes turns out to be symmetrical about the equator, unlike the measurement data. It was shown in [13] that the $\mathrm{H}^{+}$concentration decreases with increasing geomagnetic activity described by the summated diurnal $\mathrm{K}_{\mathrm{p}}$ index, but then the authors performed no separation between the influence of solar and geomagnetic activity. The only input parameter of the model taking into account factors of space weather is the solar flux index $F_{10.7}$. At some altitudes, the IRI and TTS models differ by an order of magnitude in estimation of absolute values of ion concentrations and relative role of $\mathrm{H}^{+}$and $\mathrm{He}^{+}$ ions. According to [14], the role of $\mathrm{He}^{+}$becomes important and even dominating under high solar activity, while under low activity the main components of the ionospheric plasma above the electron concentration maximum are $\mathrm{O}^{+}$and $\mathrm{H}^{+}[6]$.

The data of measurements onboard satellites of the $A E$ (Atmospheric Explorer) series were compared in [15] with calculations by the model FLIP (Field Line Interhemispheric Plasma) [16] for four ion species $\left(\mathrm{H}^{+}, \mathrm{He}^{+}, \mathrm{N}^{+}\right.$, and $\left.\mathrm{O}^{+}\right)$. The experimental data were grouped in two seasons (summer and winter), in nearnoon and near-midnight intervals of local time, and in two latitudinal bands $\left(40^{\circ}-50^{\circ}\right.$ and $\left.50^{\circ}-60^{\circ} \mathrm{N}\right)$. Since in that paper the data were analyzed within relatively short time interval, the dependence on solar and geomagnetic activity was not considered. The data were averaged also for two hemispheres with allowance made for the season. The noon ion and electron temperatures were fitting parameters of the model. The model and measured concentrations of $\mathrm{O}^{+}$and $\mathrm{H}^{+}$ ions agree well at all altitudes, while the values for $\mathrm{He}^{+}$ ions agree at heights up to $500 \mathrm{~km}$. Thus, the FLIP model describes well enough large-scale variations in ion concentrations. As for description of the density variations at smaller spatial scales and times, it is a complicated task not only for theoretical description, but for construction of an empirical model as well.

In order to construct an empirical model of ion concentrations in the topside ionosphere describing all main features of latitudinal distributions, seasonal variations, and dependencies on space weather factors, one needs long-period continuous measurements on low-apogee satellites which are moving for the most part of time near the ionospheric upper transition height. But such measurements are relatively scarse. In [17] seasonal variations, dependencies on latitude, and changes in solar activity cycle of concentrations of the main ion species at a height of about $600 \mathrm{~km}$ at latitudes of $\pm 34^{\circ}$ over the period 1994-2001 (that is, approximately over a half of solar activity cycle from minimum to maximum) are studied. At relatively high solar activity, the concentrations of $\mathrm{H}^{+}$and $\mathrm{He}^{+}$ ions were too low for detailed analysis, but high enough for estimation of the diurnal variation. During the period under study, the mean value of the $\mathrm{H}^{+}$concentration at the nighttime side was $10^{4} \mathrm{~cm}^{-3}$, which is an order of magnitude higher that the mean value at the daytime side. A high (0.83) correlation coefficient between the concentration of $\mathrm{O}^{+}$and solar activity index $F_{10.7}$ was obtained, as well as three-fold increase in the daytime concentration from 1995 to 2000 and inter-hemisphere asymmetry with the $\mathrm{O}^{+}$concentration maximum in the equinox periods at $15^{\circ} \mathrm{N}$. The seasonal variations and longitudinal dependencies of the $\mathrm{H}^{+}$and $\mathrm{O}^{+}$concentrations at a height of $1100 \mathrm{~km}$ were considered in [3] for two years of observations at high solar activity in 1978-1980 at latitudes from $70^{\circ} \mathrm{S}$ to $70^{\circ} \mathrm{N}$. For approximation of the seasonal behavior of the $\mathrm{O}^{+}$concentration we have used a harmonic function with one annual harmonics and amplitude depending linearly on solar activity level. In other words, in the final formula, only the most general features of the seasonal behavior and latitudinal dependence are taken into account. Thus, the available empirical models agree well in estimation of vertical profiles and of diurnal behavior of the $\mathrm{O}^{+}$concentration averaged over large intervals of time and latitude. The agreement is slightly worse for light ions (especially for $\mathrm{He}^{+}$). But the available data are not sufficient for a description of details of the latitudinal distribution and seasonal behavior. In the problem on the dependence of ion concentration on external factors, first of all, on solar and geomagnetic activity, there are also unsolved problems. Though the existence of these dependencies was discovered more than 40 years ago, still no separation of the influence of solar and geomagnetic activity on concentration of each of ion species has been performed.

In order to solve these problems, in this paper the data of the DEMETER satellite are used. The measurements of the three ion species $\left(\mathrm{H}^{+}, \mathrm{He}^{+}\right.$, and $\left.\mathrm{O}^{+}\right)$ are continuously conducted onboard the satellite at a height of $\sim 700 \mathrm{~km}$ at latitudes from $60^{\circ} \mathrm{S}$ to $60^{\circ} \mathrm{N}$ since 2004 [18]. In this paper, the main morphological properties, including the seasonal behavior and latitude distribution of concentrations of $\mathrm{H}^{+}, \mathrm{He}^{+}$, and $\mathrm{O}^{+}$are studied, and dependencies of the concentrations on solar and geomagnetic activity are analyzed. As far as the data set available for processing covers 


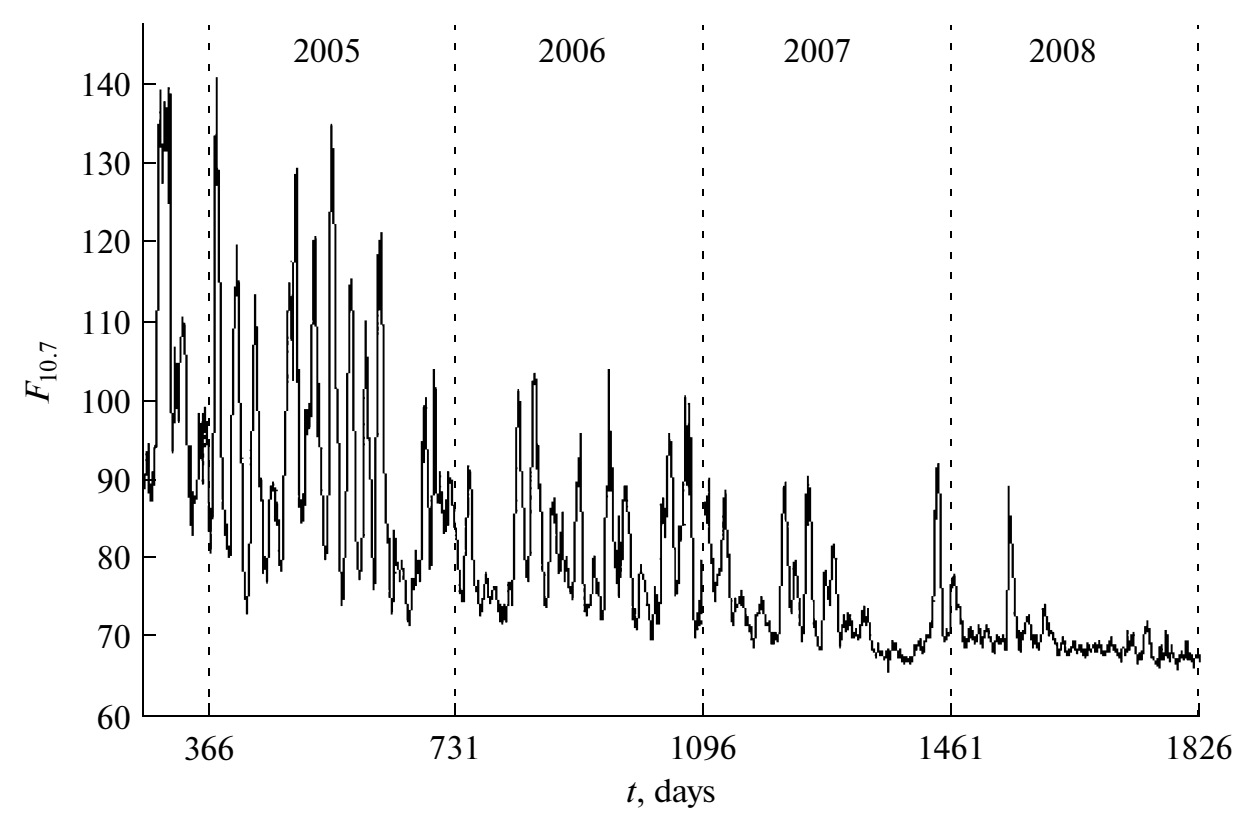

Fig. 1. Variations of the solar flux index $F_{10.7}$ in 2004-2008.

more than four years of continuous observations at approximately the same height, the ion concentration variations are studied with the better time resolution than in the previous publications. This makes it possible to reveal additional morphological features and to separate the influence of solar radiation and geomagnetic disturbances on concentrations of particular ion components.

In this paper, the results integrated over longitude are presented. A large number of papers has been dedicated to consideration of the longitudinal variation (see, for example, [9]). Ion concentrations at various longitudes in the topside ionosphere can differ severalfold due to the combination of the neutral wind, $[\mathrm{E} \times \mathbf{B}]$ drift, and tidal effects. Studies of longitudinal variation is beyond the scope of this paper, but using its results, one has to bear in mind the error related to averaging over longitude.

\section{OBSERVATIONS AND DATA PROCESSING}

Concentrations of the main components of plasma are measured onboard the DEMETER satellite continuously since 2004 (see, for example, [19]). The DEMETER satellite was launched on June 29, 2004 to a circular solar-synchronous orbit with an inclination of $98^{\circ}$ and the altitude range $710-730 \mathrm{~km}$. At the nighttime and daytime sides, the satellite orbit falls on the local time intervals 22:00-24:00 LT and 10:0012:00 LT, respectively. Concentrations of three ion species $\left(\mathrm{H}^{+}, \mathrm{He}^{+}\right.$, and $\left.\mathrm{O}^{+}\right)$are measured by the electrostatic thermal plasma analyzer developed in CETP [18]. The concentration of the main component $\mathrm{O}^{+}$is measured within the range $10^{2}-5 \cdot 10^{5} \mathrm{~cm}^{-3}$ with an accuracy of $5 \%$. The concentration of light ions was measured above the threshold value taken as $2 \%$ of the $\mathrm{O}^{+}$concentration. The early measurements onboard the Ariel- 1 satellite showed that isolines of the $\mathrm{O}^{+}$concentration lie approximately along the geomagnetic parallels [20]. In this paper, we also use the corrected geomagnetic coordinate system (CGM). The data for daytime and nighttime segments of the orbit are analyzed separately and the satellite orbit is split in geomagnetic latitude into bands $10^{\circ}$ wide. The preliminary analysis includes selection of intervals with satisfactory quality of data and averaging over time and latitude. In order to weaken the impact of rare peak values, logarithms of concentrations are analyzed.

\section{RESULTS OF DATA PROCESSING}

\subsection{Variations of Ion Concentrations within the 11-year Solar Activity Cycle}

During the observations (2004-2008), solar activity decreased (Fig. 1). Variations of the $\mathrm{H}^{+}, \mathrm{He}^{+}$, and $\mathrm{O}^{+}$concentrations are presented in Figs. 2, 3, and 4, respectively. Each panel shows results for one latitudinal band $10^{\circ}$ wide. The concentration values were averaged in a sliding 30-day window. The results for daytime and nighttime parts of the orbit are shown in the left-hand and right-hand panels, respectively.

The concentration of light ions grows with decreasing solar activity. At all latitudes at the nighttime side, stronger dependence of the $\mathrm{H}^{+}$concentration on solar activity than at the daytime side is observed. For example, within the latitudinal band $30^{\circ}-60^{\circ} \mathrm{N}$, the mean concentration of $\mathrm{H}^{+}$in summer is approximately 4.5 . $10^{2} \mathrm{~cm}^{-3}$ in 2005 , while it increases up to $1.3 \cdot 10^{3} \mathrm{~cm}^{-3}$ in 2008. In the same months, i.e., in local winter, in the 

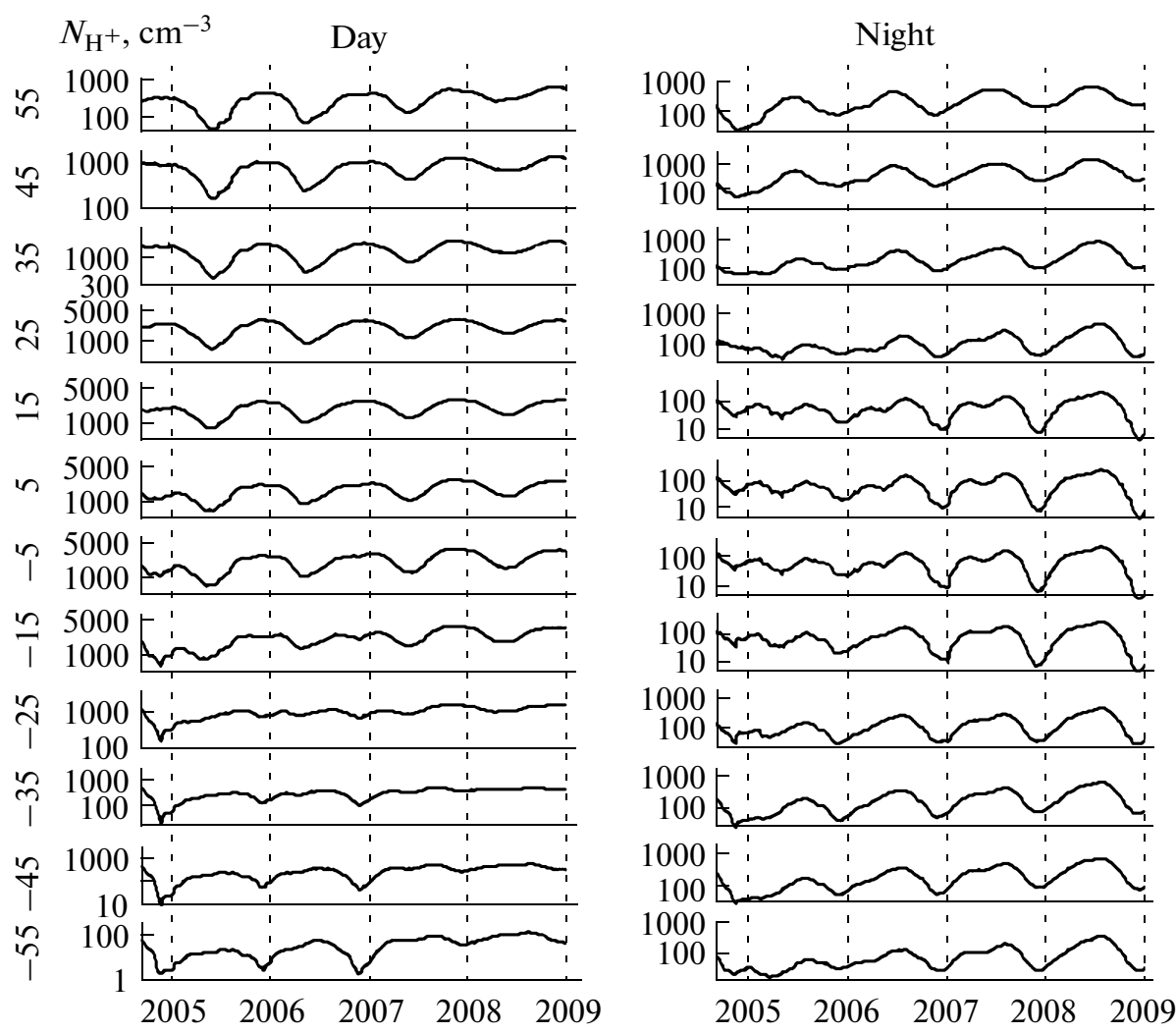

Fig. 2. Variations of the $\mathrm{H}^{+}$concentration in 2004-2008. The central latitude for each band is shown to the left from the ordinates in the left-hand panel.

Southern Hemisphere the $\mathrm{H}^{+}$concentration in 2008 is by a factor of 3 higher than in 2005: $8.4 \cdot 10^{2}$ and 2.9 . $10^{2} \mathrm{~cm}^{-3}$, respectively. On the daytime side, the $\mathrm{H}^{+}$ concentration also increases with decreasing solar activity. But the dependence of the concentration on solar activity is weaker: the maximal daytime concentration of $\mathrm{H}^{+}$in 2008 is approximately by a factor of two higher than in 2005. The variation in the $\mathrm{He}^{+}$concentration within the 11-year solar activity cycle (Fig. 3) coincides qualitatively with the variation in the $\mathrm{H}^{+}$ concentration at all latitudes both at the daytime and nighttime sides, but the difference in the $\mathrm{He}^{+}$concentration in the period of minimal (2008) and moderate (2005) solar activity is less than for $\mathrm{H}^{+}$.

Unlike the concentrations of light ions, the $\mathrm{O}^{+}$ concentration decreases in the period from 2004 to 2008 together with solar activity (Fig. 4). Depending on latitude, the $\mathrm{O}^{+}$concentration decreases from 2005 to 2008 by a factor of $3-5$. Within the $30^{\circ}-60^{\circ} \mathrm{N}$ latitudinal band, the $\mathrm{O}^{+}$concentration was $1.6 \cdot 10^{4}$ and $5 \cdot 10^{3} \mathrm{~cm}^{-3}$ in 2005 and 2008 , respectively. At low latitudes, the concentration decrease is even more substantial: from $2.0 \cdot 10^{4} \mathrm{~cm}^{-3}$ in 2005 to $5 \cdot 10^{3} \mathrm{~cm}^{-3}$ in 2008 .

Thus, long-term (on time scales of several years) variations in the light ion concentrations show an anticorrelation with variations in the $\mathrm{O}^{+}$concentration and solar activity. After the analysis of seasonal behavior of ion concentrations in the next subsection, we will return to correlations of ion concentrations with solar activity at shorter time scales for revealing physical factors governing ion concentrations in the topside ionosphere.

\subsection{Seasonal Behavior at Various Latitudes and in Local Time Intervals}

In addition to variations within solar activity cycle, the concentration of each type of ions depends systematically on latitude and local time of the year. Since within the 11-year cycle of solar activity, only annual mean values of the concentrations change substantially, while the relative seasonal variations in concentrations stay almost unchangeable, it is convenient to analyze the seasonal variations in the concentration logarithms averaged over the observational period.

The seasonal behavior of logarithms of concentrations of three ion species averaged over all years of observations is shown in Fig. 5 for the latitudinal interval $40^{\circ}-50^{\circ}$ both in the Northern and Southern Hemispheres. The seasonal behavior differs substantially for light ions and $\mathrm{O}^{+}$. The main qualitative features of the seasonal behavior of concentration of three ion species are presented in Table 1. The table 

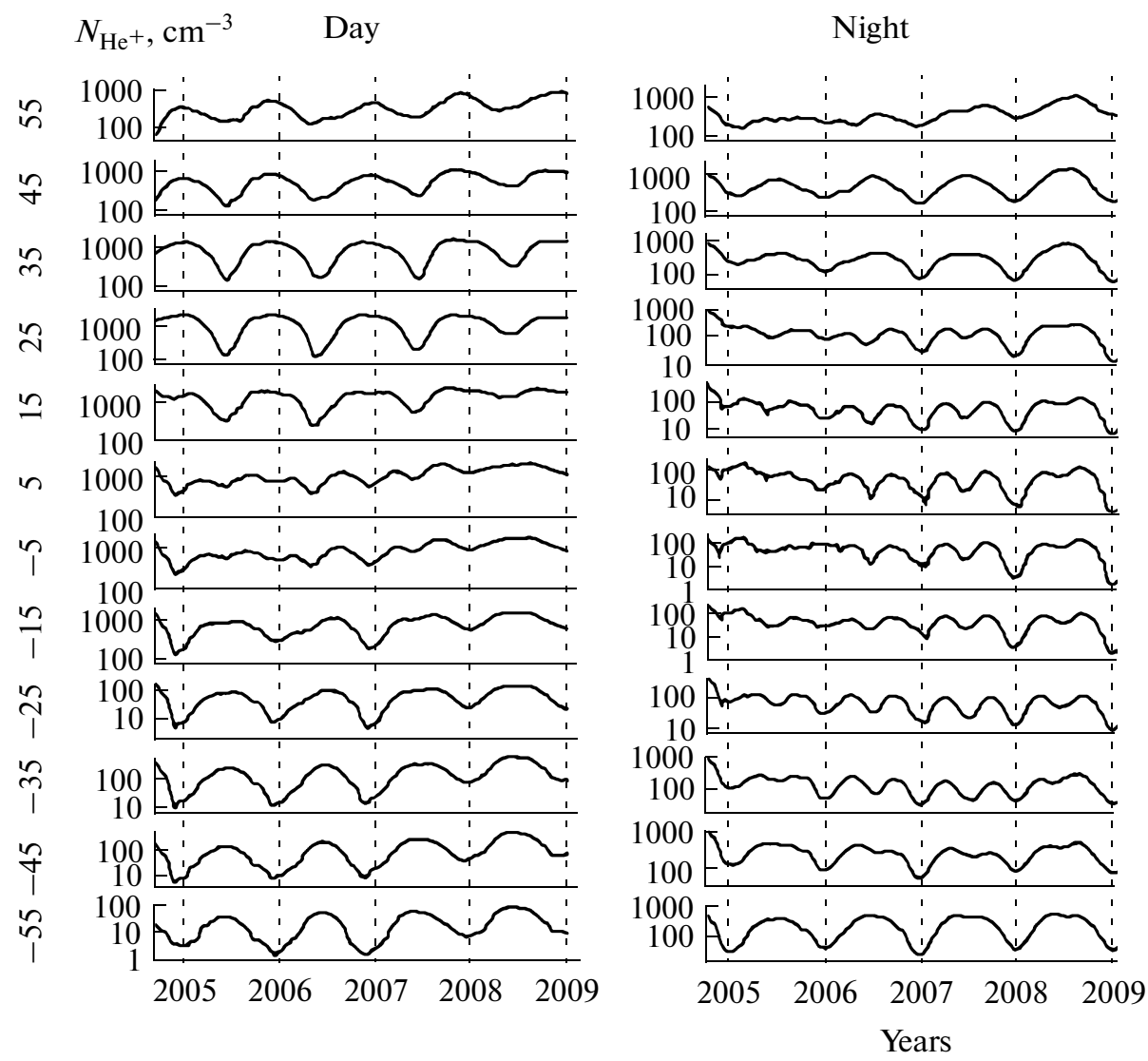

Fig. 3. Variations of the $\mathrm{He}^{+}$concentration. The figure format is the same as in Fig. 2.

presents the position of the yearly maximum concentration $T_{\max }$, maximal concentration $N_{\max }$, and ratio of the maximal and minimal yearly concentrations $N_{\max } / N_{\min }$. The Day/Night and N/S indices correspond to the daytime and nighttime sides and to the Northern and Southern Hemispheres, respectively. For all three types of ions at the daytime side in the Northern Hemisphere, larger values of the maximal yearly concentration, $N_{\max }$ are observed, while in the Southern Hemisphere, larger relative amplitudes of the seasonal behavior $N_{\max } / N_{\min }$ are observed. The main differences in the seasonal behavior between $\mathrm{O}^{+}$ and light ions are as follows.

- seasonal behavior in its classical form is observed only for $\mathrm{O}^{+}$, while for light ions, in addition to season, global factors play an important role and this fact leads to different forms of the seasonal behavior curve in two hemispheres relative to local time of the year at the daytime side and to the existence of a global maximum of concentration in October on the nighttime side;

- a sharp inter-hemisphere asymmetry is observed in the latitudinal distribution of light ion concentrations: the maximal yearly concentration at the daytime side in the Northern Hemisphere is an order of magnitude higher than in the Southern Hemisphere, while for $\mathrm{O}^{+}$the ratio of maximal yearly concentrations $N_{\mathrm{O}, \max , \mathrm{N}} / N_{\mathrm{O}, \max , \mathrm{S}} \approx 2$.

Seasonal variations in the ion concentrations in the near-equatorial region are shown in Fig. 6 in the same format as in Fig. 5. For all three ion species, the difference in the seasonal behavior between the hemispheres at low latitudes vanishes, but the seasonal behavior itself remains substantial, and some features appear in it, different from those observed at middle latitudes. The main features of the seasonal behavior in the near-equatorial region are presented in Table 2 (designations are the same as in Table 1). Since at the near-equatorial latitudes, the seasonal behavior in both hemisphere almost coincides, the Table 2 shows the parameter values averaged over the band $-10^{\circ}<\Phi<10^{\circ}$. For all ion components at the daytime side, larger concentrations are observed, while the relative amplitude of the seasonal behavior $N_{\max } / N_{\min }$ is higher at the nightside. At the dayside where the relative amplitude of the seasonal behavior is small, the positions of maxima and minima in the seasonal behavior curve are different for all three types of ions. At the nightside, there exist the following qualitative differences in the seasonal behavior of the concentrations of $\mathrm{O}^{+}$and light ions: 

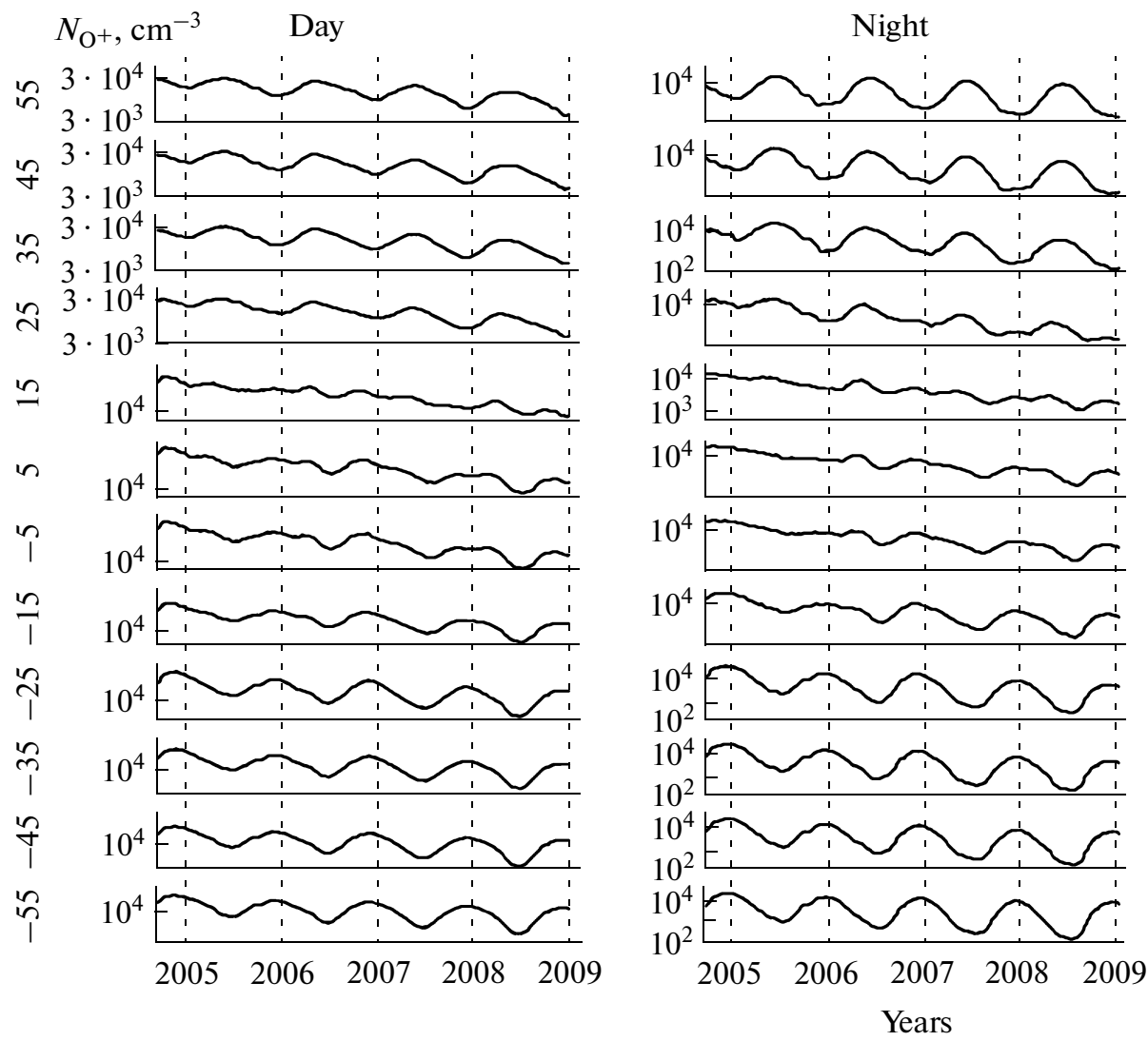

Fig. 4. Variations of the $\mathrm{O}^{+}$concentration. The figure format is the same as in Fig. 2.

- seasonal behavior curves for $\mathrm{H}^{+}$and $\mathrm{He}^{+}$have two maxima in April-May and in October, while the curve for $\mathrm{O}^{+}$has the only maximum in February;

- the relative amplitude of the seasonal behavior, $N_{\max } / N_{\min }$ is substantially higher for light ions than for $\mathrm{O}^{+}$.

Thus, the seasonal behavior of the $\mathrm{O}^{+}$concentration is governed by the local time of the year, while global factors are important (and even dominating for some intervals of latitudes and local times) for variations in the concentrations of light ions during the year. In order to reveal the parameters governing changes in the concentrations of $\mathrm{O}^{+}$and light ions, in the next subsection we will study the dependencies of ion concentrations at the dayside separately from solar and geomagnetic activity on the time scales from several days to several weeks.

\subsection{Variations in Ion Concentrations on Time Scales from Several Days to Several Weeks. Dependences on Solar and Geomagnetic Activity}

The above consideration has shown that the dependencies of ion concentrations in the topside ionosphere on time of the year and solar activity at time scales from several months to several years differ substantially for $\mathrm{O}^{+}$and light ions. The seasonal variation in its classical form exists only for the $\mathrm{O}^{+}$concentra- tion. The summer yearly maximum in the concentration and positive correlation with solar activity within the 11 -year cycle show that the $\mathrm{O}^{+}$concentration is governed mainly by solar radiation. Since on large time scales, the correlation of ion concentration with solar activity can be an artifact of the dependence on other parameters also correlating with solar activity, we chose for more detailed study one year, 2005, when the 27-day cycle related to the rotation of the Sun is distinctly seen in solar indices as it usually takes place at the decline phase of the 11-year solar cycle. Figure 7 shows the results of comparison of variations in the $\mathrm{O}^{+}$ concentration and solar activity during nine months from January to September 2005. The top panel shows logarithm of the $\mathrm{O}^{+}$concentration at the daytime segments of the orbit. One point in the figure corresponds to a daily mean value of the concentration logarithm. The middle panel shows the daily mean values of the solar radiation flux $F_{10.7}$. In January-June, 5 maxima in the $F_{10.7}$ index with a distinct 27-day period are seen. After the phase break, three more maxima with the same period (the first of them falls on $t=132$ days) are observed. The three last cycles in August-September have a changed period $T=22$ days. In the bottom panel, the running 30-point correlation coefficient $C_{F 10.7-\mathrm{O}+}$ between the logarithm of the $\mathrm{O}^{+}$concentra- 

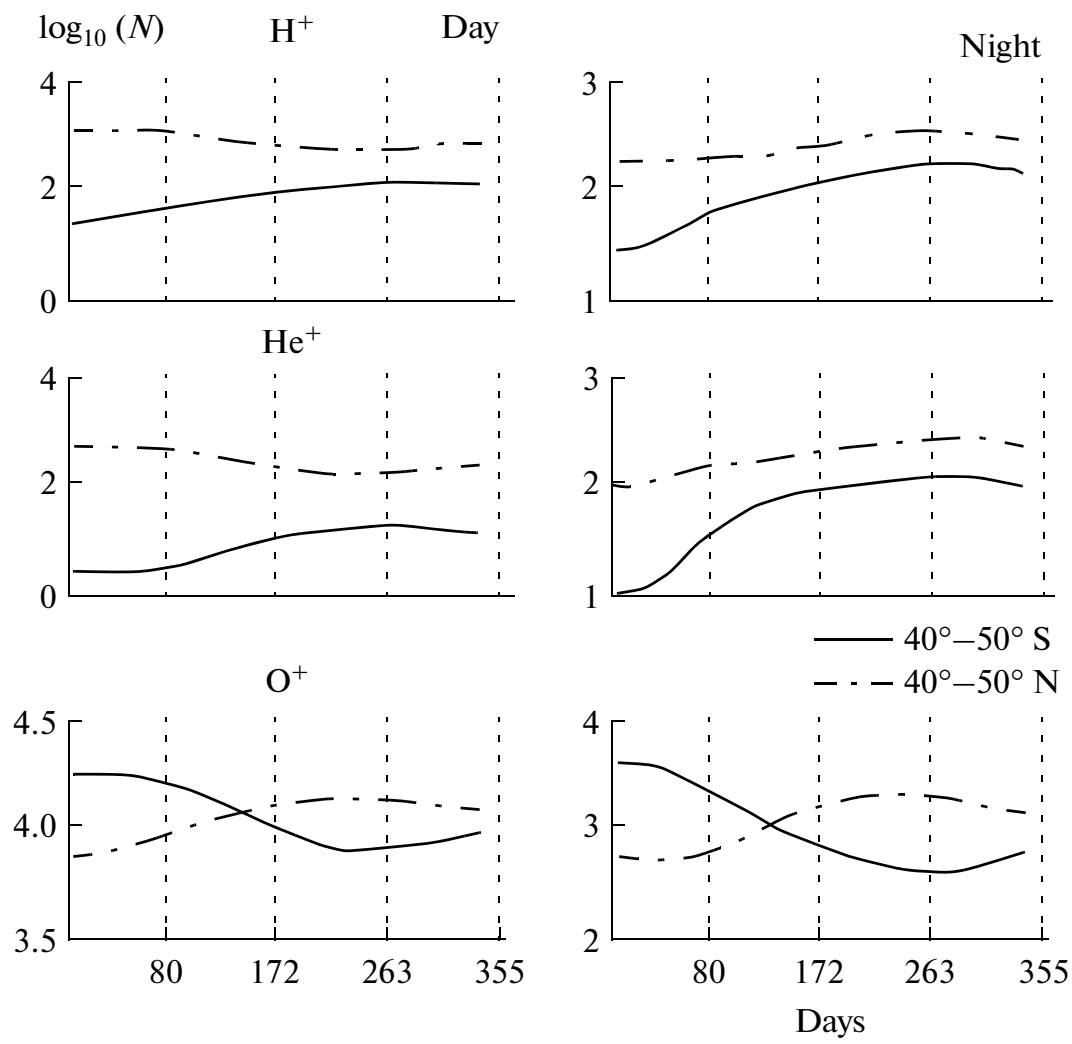

Fig. 5. Seasonal behavior of logarithm of the concentrations of three ion species at middle latitudes averaged over the entire observational period. The vertical dashed lines show the positions of equinoxes and solstices.

tion and solar activity index $F_{10.7}$ is shown. We remind that one point corresponds to the value of the concentration logarithm averaged over one day at the daytime segment of the orbit, that is, the 30 -point correlation coefficient at the absence of gaps in the data corresponds to a month of observations. The correlation coefficient $C_{F 10.7-\mathrm{O}+}$ is positive everywhere and for the majority of intervals exceeds 0.5 , and the positions of almost all maxima in the $F_{10.7}$ index and $\mathrm{O}^{+}$concentration coincide with an accuracy of one day. Note that the coincidence of positions of maxima is observed at changing phase and period. The value of the correlation coefficient averaged over nine months $\left\langle C_{F 10.7-\mathrm{O}+}\right\rangle=$ 0.69 . Figure 7 shows values of the concentration logarithms for one latitudinal band, but similar picture is observed along the entire profile: at all latitudes the positions of the maxima in $\mathrm{O}^{+}$concentration are constant and the correlation coefficient $C_{F 10.7-\mathrm{O}+}$ is substantially positive.

Figure 8 shows the results for the same time interval for the $\mathrm{H}^{+}$concentration within the latitudinal band $50^{\circ}-60^{\circ} \mathrm{N}$. Logarithm of the $\mathrm{H}^{+}$concentration and the solar activity index $F_{10.7}$ are shown in the top and middle panels, respectively. The bottom panel shows the running 30-point correlation coefficient $C_{F 10.7-\mathrm{H}+}$ between the $F_{10.7}$ index and logarithm of the $\mathrm{H}^{+}$concentration. On the average, the concentration of $\mathrm{H}^{+}$ anti-correlates with the $\mathrm{O}^{+}$concentration and solar activity. The value of the correlation coefficient averaged over nine months $\left\langle C_{F 10.7-\mathrm{H}+}\right\rangle=-0.51$. Unlike the case of $\mathrm{O}^{+}$, the minima in $\log \left(N_{\mathrm{H}+}\right)$ are often shifted by several days relative to the solar activity maxima. This can be caused by the fact that the concentration of $\mathrm{H}^{+}$ depends on solar activity not directly, but through geo-

Table 1. Main features of the seasonal behavior at middle latitudes

\begin{tabular}{l|c|c|c}
\hline & $\mathrm{O}^{+}$ & $\mathrm{H}^{+}$ & $\mathrm{He}^{+}$ \\
\hline$T_{\max , \mathrm{N}, \text { Day }}$, months & 8 & $1-2$ & $1-2$ \\
$T_{\max , \mathrm{S}, \text { Day }}$, months & 2 & 10 & 10 \\
$T_{\max , \mathrm{N}, \text { Night }}$, months & 8 & 10 & 10 \\
$T_{\max , \mathrm{S}, \text { Night }}$, months & 2 & 10 & 10 \\
$N_{\max , \mathrm{N}, \text { Day }}, \mathrm{cm}^{-3}$ & $1.8 \cdot 10^{4}$ & $10^{3}$ & 560 \\
$N_{\max , \mathrm{S}, \text { Day }}, \mathrm{cm}^{-3}$ & $1.4 \cdot 10^{4}$ & 125 & 20 \\
$N_{\max , \mathrm{N}, \text { Night }}, \mathrm{cm}^{-3}$ & $4 \cdot 10^{3}$ & 350 & 260 \\
$N_{\max , \mathrm{S}, \text { Night }}, \mathrm{cm}^{-3}$ & $2.1 \cdot 10^{3}$ & 190 & 130 \\
$N_{\max , \mathrm{N}, \text { Day }} / N_{\min , \mathrm{N}, \text { Day }}$ & 1.7 & 2 & 3.5 \\
$N_{\max , \mathrm{S}, \text { Day }} / N_{\min , \mathrm{S}, \text { Day }}$ & 2.3 & 6 & 8.5 \\
$N_{\max , \mathrm{N}, \text { Night }} / N_{\min , \mathrm{N}, \text { Night }}$ & 4 & 1.9 & 1.6 \\
$N_{\max , \mathrm{S}, \text { Night }} / N_{\min , \mathrm{S}, \text { Night }}$ & 10 & 7 & 11 \\
\hline
\end{tabular}



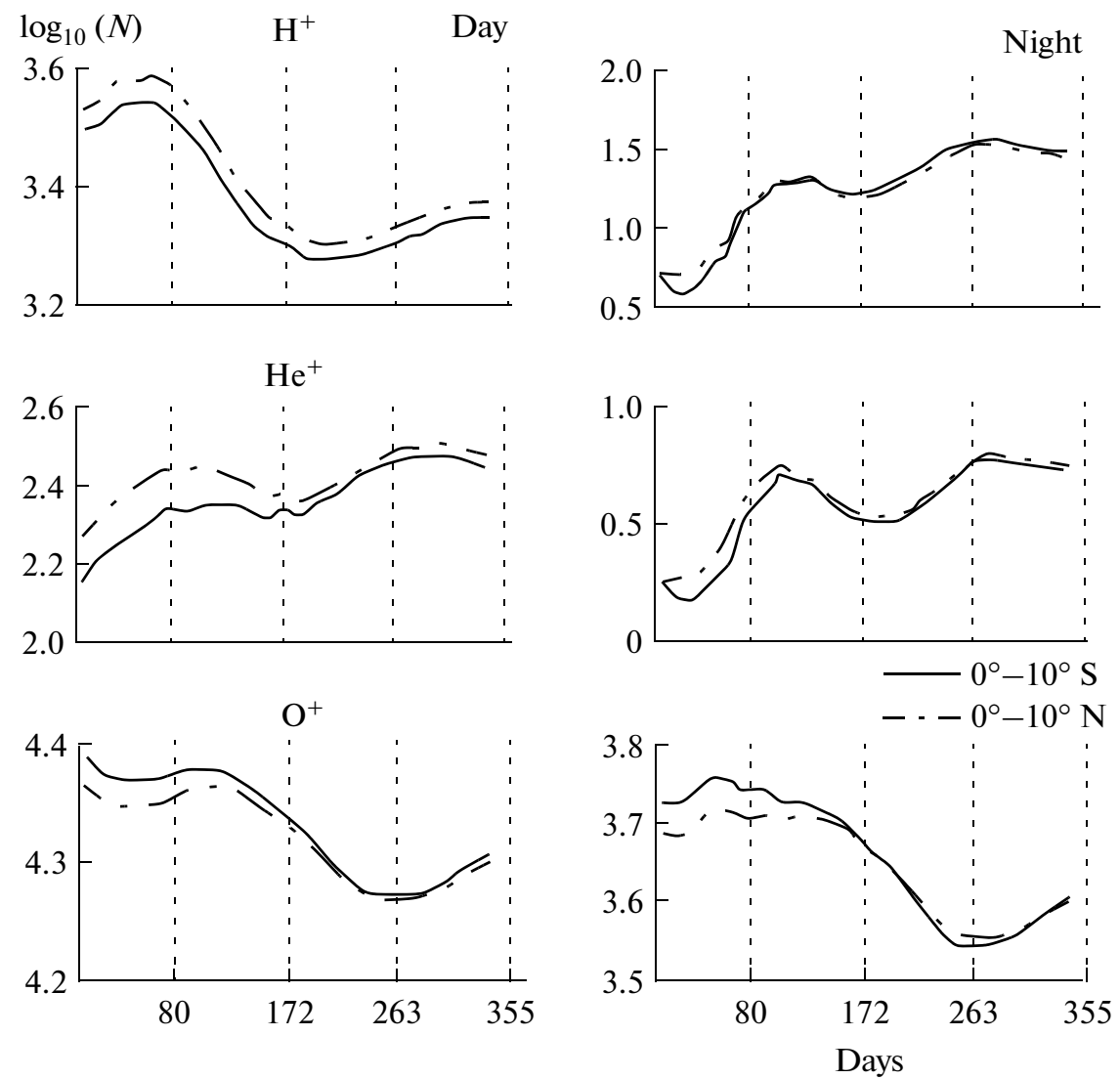

Fig. 6. Seasonal behavior of logarithm of the concentrations of three ion species at low latitudes averaged over the entire observational period. The figure format is the same as in Fig. 5.

magnetic activity. In order to check this assumption, we compare variations in the $\mathrm{H}^{+}$concentration and geomagnetic activity described by the $D_{\text {st }}$ index (we remind that the negative values of the index correspond to high geomagnetic activity).

Logarithm of the $\mathrm{H}^{+}$concentration within the latitudinal band $50^{\circ}-60^{\circ} \mathrm{N}$ and geomagnetic activity index $D_{\text {st }}$ are shown in Fig. 9. Logarithm of the $\mathrm{H}^{+}$ concentration is shown in the top panel, the $D_{\text {st }}$ index

Table 2. Main features of the seasonal behavior at low latitudes

\begin{tabular}{l|c|c|c}
\hline & $\mathrm{O}^{+}$ & $\mathrm{H}^{+}$ & $\mathrm{He}^{+}$ \\
\hline$T_{\max , \text { Day }}$, months & 1 and 4 & $2-3$ & $3-4$ and $11-12$ \\
$T_{\max , \text { Night }}$, months & 2 & $4-5$ and 10 & $4-5$ and 10 \\
$N_{\max , \text { Day }}, \mathrm{cm}^{-3}$ & $2.5 \cdot 10^{4}$ & $3.8 \cdot 10^{3}$ & 310 \\
$N_{\max , \text { Night }}, \mathrm{cm}^{-3}$ & $5.7 \cdot 10^{3}$ & 35 & 6 \\
$N_{\max , \text { Day }} / N_{\min , \text { Day }}$ & 1.4 & 1.9 & 1.7 \\
$N_{\max , \text { Night }} / N_{\min , \text { Night }}$ & 1.7 & 9 & 4 \\
\hline
\end{tabular}

is shown in the middle panel, and the bottom panel shows the running 30-point correlation coefficient between $D_{\mathrm{st}}$ and $\lg \left(N_{\mathrm{H}+}\right)-C_{D_{\mathrm{st}-\mathrm{H}+}}$. The correlation coefficient averaged over nine months $\left\langle C_{D_{\mathrm{st}}-\mathrm{H}+}\right\rangle=0.71$ and the positions of all pronounced minima in $D_{\mathrm{st}}$ agree with a good accuracy with the positions of minima in the $\mathrm{H}^{+}$concentration. At lower latitudes the absolute value of the correlation coefficient decreases, but the coincidence of the minima positions remains good. Low values of the correlation coefficient $C_{D \mathrm{st}-\mathrm{H}+}$ are observed during approximately a month from July 10, 2005 to August 10, 2005 , when geomagnetic activity was low and there was no magnetic storms with $D_{\mathrm{st}}<-100 \mathrm{nT}$. Note that at the same time, the absolute values of the correlation coefficient $C_{F 10.7-\mathrm{H}+}$ exceed the mean values over the entire observational period, that is, the anti-correlation between the $\mathrm{H}^{+}$concentration and solar activity known from publications reveals itself. For the remaining intervals and on the average over the period considered, geomagnetic activity influences the $\mathrm{H}^{+}$ concentration stronger than solar activity.

\section{DISCUSSION AND CONCLUSIONS}

The performed analysis of the measurements onboard the DEMETER satellite made it possible to 

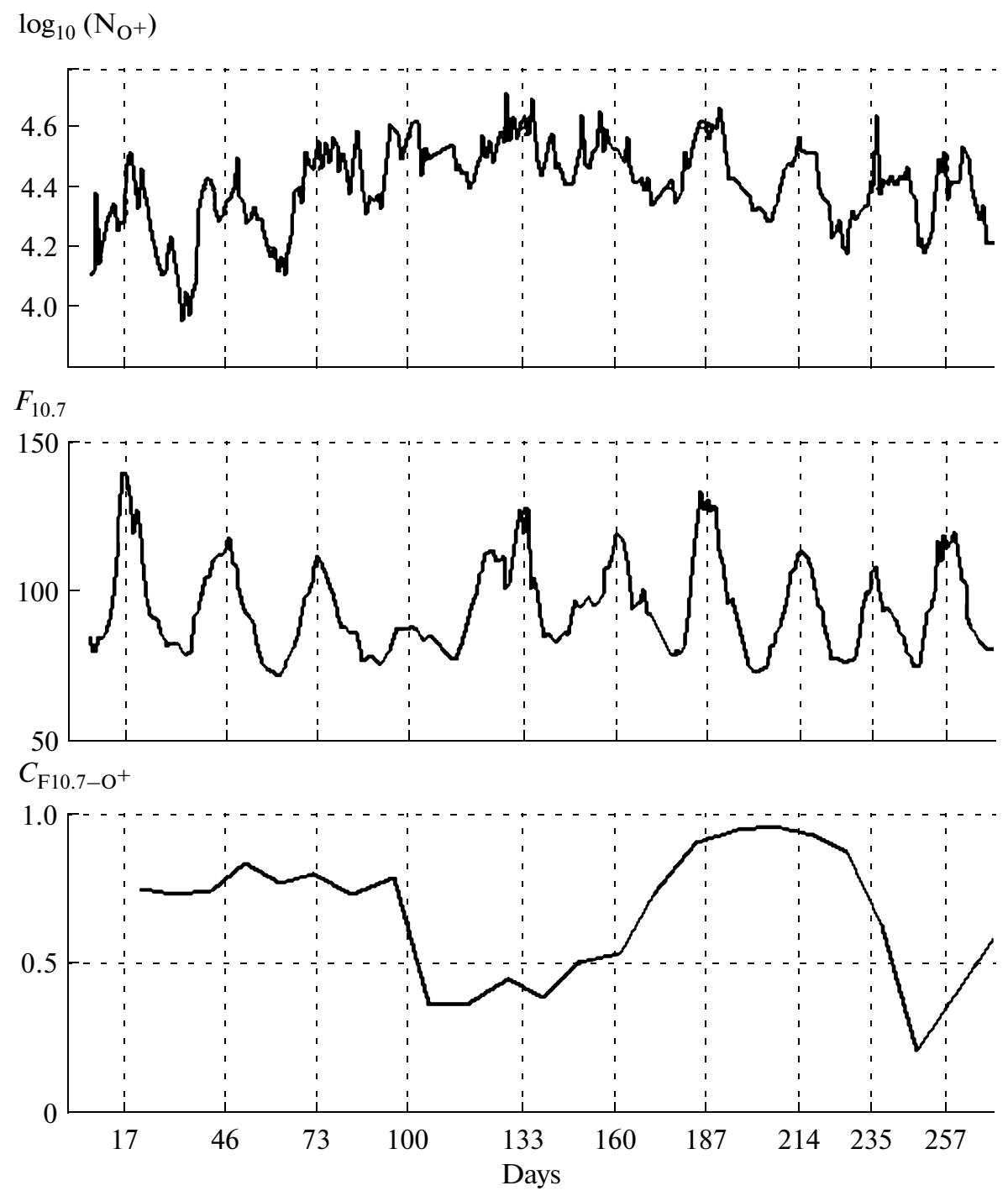

Fig. 7. Logarithm of the $\mathrm{O}^{+}$concentration within the latitudinal band $20^{\circ}-30^{\circ} \mathrm{N}$, solar activity index $F_{10.7}$, and running 30 -point correlation coefficient $\mathrm{C}_{F 10.7-\mathrm{O}+}$ between the $F_{10.7}$ index and logarithm of the concentration. Positions of $F_{10.7}$ index maxima are shown by thin dashed vertical lines.

reveal new qualitative features in the seasonal behavior and latitudinal distribution of ion concentrations in the topside ionosphere relative to the IRI model [1].

Variations of the concentrations of $\mathrm{H}^{+}, \mathrm{He}^{+}$, and $\mathrm{O}^{+}$ions within the 11-year cycle of solar activity agree with the variations predicted by the IRI [1] and TTS [10] models: at decreasing solar activity, the $\mathrm{O}^{+}$concentration decreases, while the concentrations of light ions increase.

Even qualitatively, the seasonal behavior obtained on the basis of the DEMETER measurements coincides with the IRI results only partially. The most substantial differences are observed for light ions. In Fig. 10, the seasonal behavior of logarithm of the $\mathrm{H}^{+}$ concentration obtained in measurements onboard the DEMETER satellite is compared with the results of the IRI model within two latitudinal intervals in both hemispheres at the daytime and nighttime sides. Since IRI predicts absolute values of the $\mathrm{H}^{+}$concentrations exceeding several times the experimental values, Fig. 10 shows normalized results of calculations by IRI. The normalizing coefficients for each latitude and local time are given in the caption to Fig. 10. The main differences in the seasonal behavior of light ion concentrations according to the DEMETER measurements and IRI are the following:

- according to the DEMETER data, the substantial inter-hemisphere asymmetry in the daytime concentration of light ions exists at middle latitudes even near equinoxes;

- according to the DEMETER data, the concentrations of light ions at middle latitudes at the nightside have a common October maximum in both hemi- 

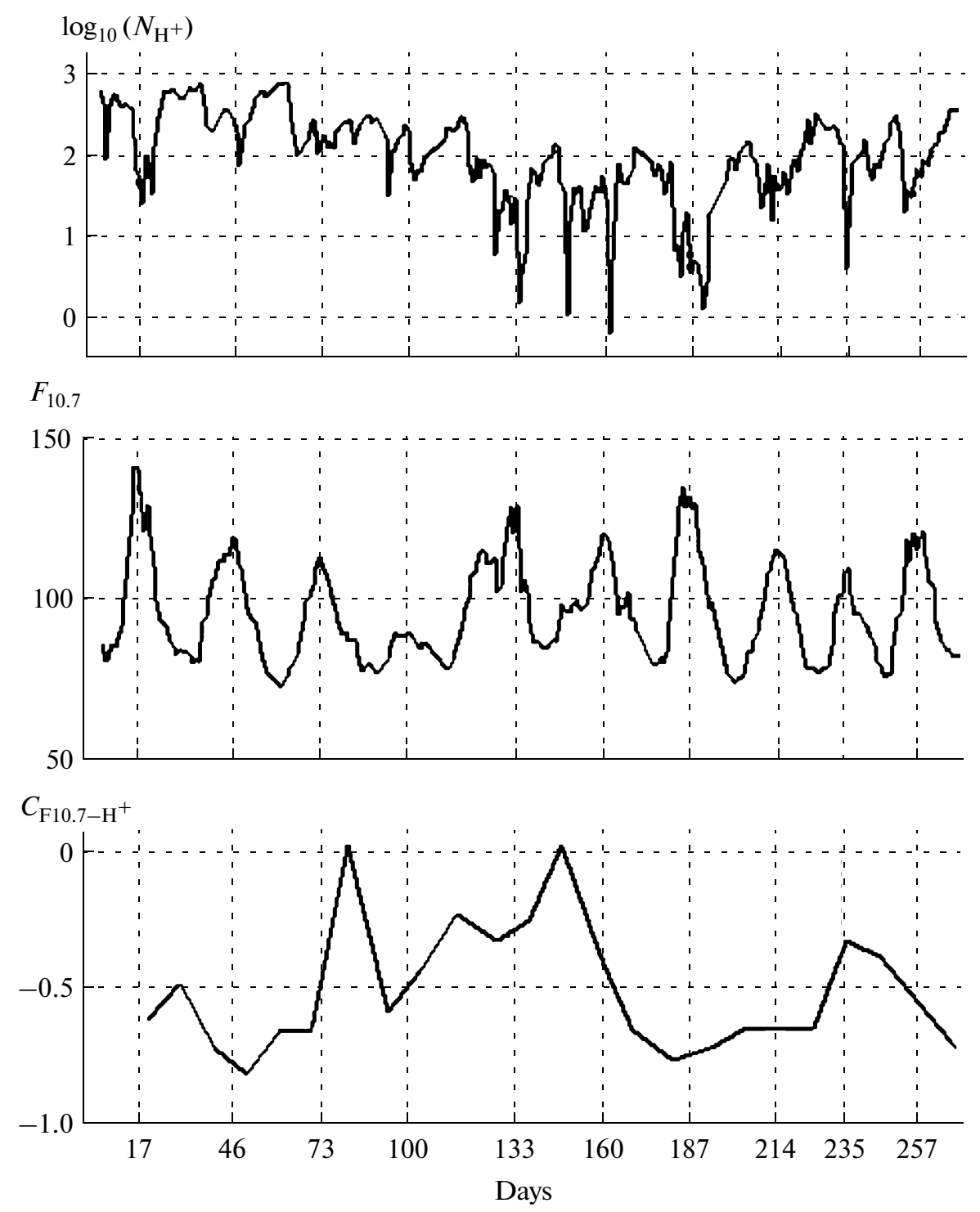

Fig. 8. Logarithm of the $\mathrm{H}^{+}$concentration within the latitudinal band $50^{\circ}-60^{\circ} \mathrm{N}$, solar activity index $F_{10.7}$, and running 30 -point correlation coefficient $C_{F 10.7-\mathrm{H}+}$ between the $F_{10.7}$ index and logarithm of the concentration.

spheres, unlike IRI which predicts two equivalent maxima near equinoxes;

- in the near-equatorial region, according to the DEMETER data, there is a qualitative difference between the seasonal behavior at the daytime and nighttime sides (the $\mathrm{H}^{+}$concentration has one maximum at the dayside and two maxima at the nightside), while IRI predicts a seasonal behavior with two maxima at low latitudes both at the daytime and nighttime sides;

- according to the DEMETER data, the positions of maxima and minima in the seasonal behavior are shifted by $1-1.5$ months relative to their position according to IRI.
The annual mean values of ion concentrations according to the DEMETER data are closer to the values from the TTS model than to the IRI model, but averaging over time performed in the TTS model makes it impossible to take into account the qualitative features in the seasonal behavior described above.

The analysis of variations in ion concentrations on the scales from several days to several weeks made it possible to separate the impact of solar and geomagnetic activity on concentration of each type of ions. The conclusion (known from publications) on antiphase change in the concentrations of $\mathrm{O}^{+}$and light ions in the dependence on solar activity is true for the 11-year cycle, but is invalid for variations with shorter time scales, in particular for the 27-day solar cycle 


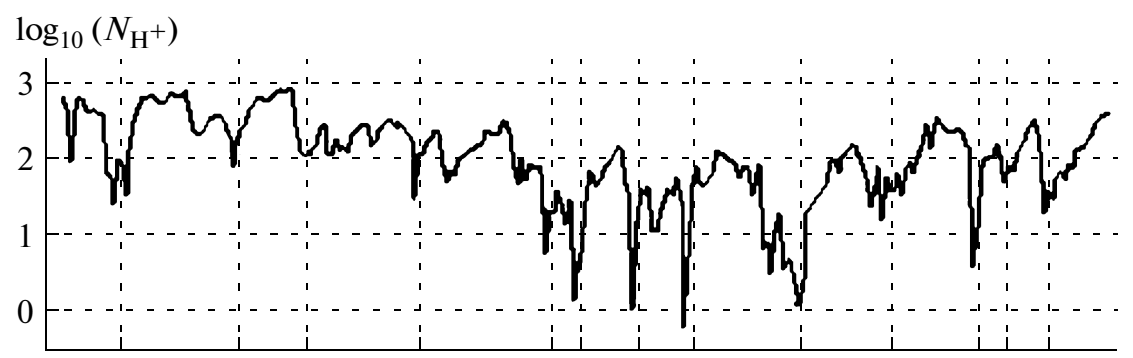

$$
D_{\text {st }}, \mathrm{nT}
$$
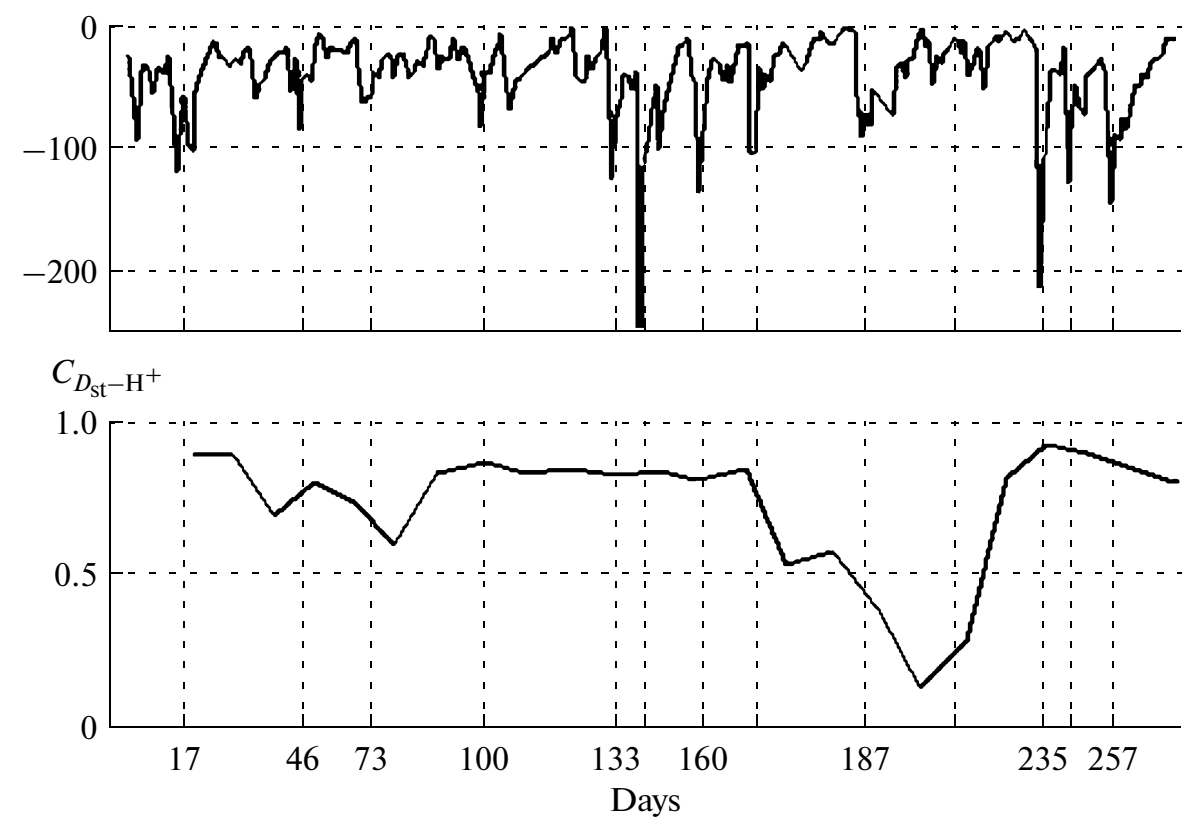

Fig. 9. Logarithm of the $\mathrm{H}^{+}$concentration within the latitudinal band $50^{\circ}-60^{\circ} \mathrm{N}$, the $D_{\mathrm{st}}$ index, and running 30 -point correlation coefficient $C_{D_{\mathrm{st}}-\mathrm{H}+}$ between the $D_{\mathrm{st}}$ index and logarithm of the concentration.

related to the solar rotation due to different dependence of concentrations of $\mathrm{O}^{+}$and light ions on solar and geomagnetic activity.

Variations of the $\mathrm{O}^{+}$concentrations at a height of $700 \mathrm{~km}$ are governed mainly by solar radiation. It is confirmed by the positive correlation with solar activity in the 11-year cycle and at variations on time scales from several days to several months. The seasonal behavior with a maximum on late local summer, almost similar shape of the curve of the seasonal behavior at all latitudes, and the low-latitude global maximum in the concentration are results of the determining influence of solar radiation on the $\mathrm{O}^{+}$ concentration.

Variations of the concentrations of $\mathrm{H}^{+}$and $\mathrm{He}^{+}$in the 11-year cycle of solar activity show the negative correlation with variations in the $\mathrm{O}^{+}$concentration and solar activity known from publications [7, 21]. In addition to the dependence on season itself, in the seasonal behavior of the light ions concentration appears (and even dominates at the nightside at middle latitudes) a dependence on global factors: the October maximum of the $\mathrm{H}^{+}$concentration is observed simultaneously in both hemispheres. On the time scales from several days to several weeks, the correlation coefficient between the logarithm of the $\mathrm{H}^{+}$concentration and $D_{\mathrm{st}}$ index of geomagnetic activity, $C_{D \mathrm{st}-\mathrm{H}+}$, is higher than with the solar activity index, the values of $C_{D s t-\mathrm{H}+}$ being higher at middle and subauroral latitudes than at low latitudes. The revealed features of the time variations and latitudinal distributions of the light ion concentrations confirm the statement that variations in the light ion concentrations both in the topside ionosphere and in the plasmasphere [23] are governed first of all by geomagnetic activity.

It is evident from our consideration that the correlation coefficients vary depending on the governing parameter level. For example, the correlation coefficient between logarithm of the $\mathrm{H}^{+}$concentration and $D_{\text {st }}$ index decreases in the periods of low geomagnetic activity. A similar regularity is seen for the relation between solar activity and the $\mathrm{O}^{+}$concentration. Thus, the dependence of concentrations on solar and 

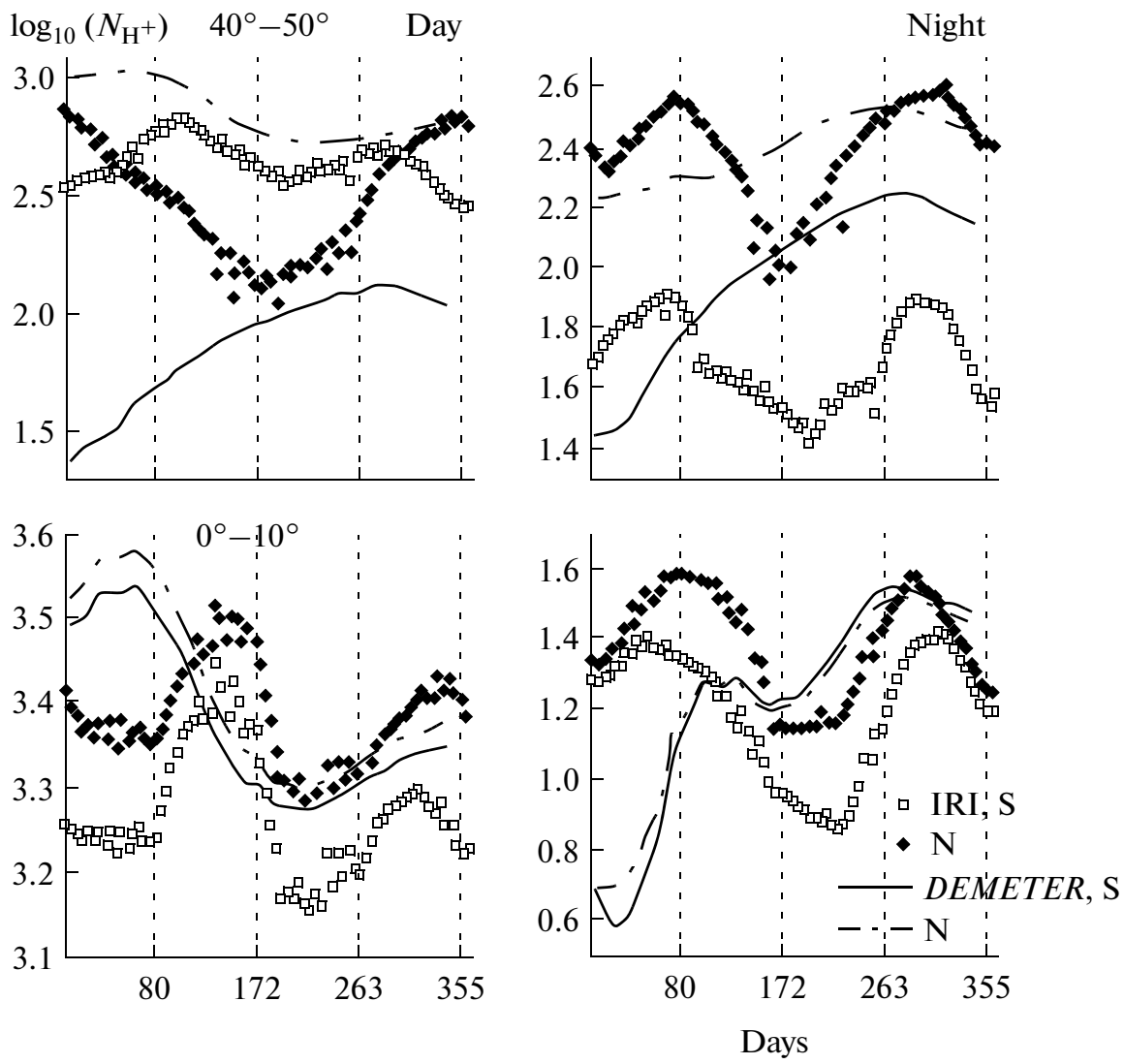

Fig. 10. Logarithm of the $\mathrm{H}^{+}$concentration within the latitudinal bands $40^{\circ}-50^{\circ}$ and $0^{\circ}-10^{\circ}$. The downward shift of the calculated curves is 0.5 for the dayside and 2 and 3 for the nightside at middle and low latitudes, respectively. The vertical dashed lines show the positions of equinoxes and solstices.

geomagnetic activity is not reduced to a simple linear dependence, as it has been assumed in [3].

The analysis of variations of ion concentrations in the topside ionosphere performed in this paper can be continued in two directions: elaborating a quantitative description of mean values of ion concentrations and studying irregular short-term variations of ion concentrations. Irregular variations on the time scales from tens of minutes to a day till now were not taken into account in empirical models. However, at least under strong disturbances, ion concentrations in the topside ionosphere vary several-fold during tens of minutes [22], i.e., amplitudes of irregular variations are comparable to the amplitudes of the regular variations considered above. Thus, inclusion into a model of statistical parameters of short-term irregular variations can be important for description of a disturbed state of the ionosphere.

\section{REFERENCES}

1. Bilitza, D. and Reinisch, B., International Reference Ionosphere 2007: Improvements and New Parameters, Adv. Space Res., 2008, vol. 42, p. 599.

2. Gonzalez, S.A. and Sulzer, M.P., Detection of $\mathrm{He}^{+}$ Layering in the Topside Ionosphere over Arecibo during
Equinox Solar Minimum Conditions, Geophys. Res. Lett., 1996, vol. 23, p. 2509.

3. Iwamoto, I., Sagawa, E., and Watanabe, S., Dependence of the Topside Ion Composition on the Solar Flux and Its Implication to IRI Model, $A d v$. Space Res., 2000, vol. 25, p. 197.

4. Yue, X.A., Schreiner, W.S., Lei, J.H., et al., Climatology of Ionospheric Upper Transition Height Derived from COSMIC Satellites during the Solar Minimum of 2008, J. Atmos. Sol.-Terr. Phys., 2010, vol. 72, p. 1270.

5. Evans, J.V. and Holt, J.M., Nighttime Proton Fluxes at Millstone Hill, Planet. Space Sci., 1978, vol. 26, p. 727.

6. Gonzalez, S.A., Fejer, B.G., Heelis, R.A., and Hanson, W.B., Ion Composition of the Topside Equatorial Ionosphere during Solar Minimum, J. Geophys. Res., 1992, vol. 97, p. 4299.

7. Taylor, H.,Jr., Brinton, H., Pharo, M., and Rahman, N., Thermal Ions in the Exosphere; Evidence of Solar and Geomagnetic Control, J. Geophys. Res., 1968, vol. 73, p. 5521.

8. Kutiev, I., Heelis, R., and Sanatani, S., The Behavior of the $\mathrm{O}^{+} / \mathrm{H}^{+}$Transition Level at Solar Maximum, J. Geophys. Res., 1980, vol. 85, p. 2366.

9. Bankov, L., Heelis, R., Parrot, M., et al., WN4 Effect on Longitudinal Distribution of Different Ion Species in the Topside Ionosphere at Low Latitudes by Means 
of DEMETER, DMSP-F13, and DMSP-F15 Data, Ann. Geophys., 2009, vol. 27, p. 2893.

10. Truhlik, V., Triskova, L., and Smilauer, J., Manifestation of Solar Activity in the Global Topside Ion Composition-A Study Based on Satellite Data, Ann. Geophys., 2005, vol. 23, p. 2511.

11. Triskova, L., Truhlik, V., and Smilauer, J., An Empirical Model of Ion Composition in the Outer Ionosphere, Adv. Space Res., 2003, vol. 31, p. 653.

12. Triskova, L., Truhlik, V., and Smilauer, J., On Possible Improvements of Outer Ionosphere Ion Composition Model in IRI, Adv. Space Res., 2002, vol. 29, p. 849.

13. Triskova, L., Truhlik, V., and Smilauer, J., Study of Major Ions Distribution in the Outer Ionosphere in the Solar Maximum, Adv. Space Res., 2000, vol. 25, p. 193.

14. Gonzalez, S.A., Sulzer, M.P., Nicolls, M.J., and Kerr, R.B., Solar Cycle Variability of Nighttime Topside Helium Ion Concentrations over Arecibo, J. Geophys. Res., 2004, vol. 109, p. A07302. doi: 10.1029/2003JA010100.

15. Craven, P.D., Comfort, R.H., Richards, P.G., and Grebowsky, J.M., Comparisons of Modeled $\mathrm{N}^{+}, \mathrm{O}^{+}, \mathrm{H}^{+}$, and $\mathrm{He}^{+}$in the Midlatitude Ionosphere with Mean Densities and Temperatures from Atmosphere Explorer, J. Geophys. Res., 1995, vol. 100, p. 257.

16. Richards, P. and Torr, D., Seasonal, Diurnal, and Solar Cyclical Variations of the Limiting $\mathrm{H}^{+}$Flux in the Earth's Topside Ionosphere, J. Geophys. Res., 1985, vol. 90 , p. 5261 .
17. Borgohain, A. and Bhuyan, P.K., Solar Cycle Variation of Ion Densities Measured by SROSS C2 and FORMOSAT-1 over Indian Low and Equatorial Latitudes, J. Geophys. Res., 2010, vol. 115, p. A04309. doi: 10.1029/2009JA014424.

18. Berthelier, J.-J., Godefroy, M., and Leblanc, F., et at., IAP, the Thermal Plasma Analyzer on DEMETER, Planet. Space Sci., 2006, vol. 54, p. 487.

19. Cussac, T., Clair, M.-A., Ultre-Guerard, P., et al., The Demeter Microsatellite and Ground Segment, Planet. Space Sci., 2006, vol. 54, p. 413.

20. Bowen, P.J., Boyd, R.L.F., Raitt, W.J., and Willmore, A.P., Ion Composition of the Upper F-Region, Proc. R. Soc. London, Ser. A, 1964, vol. 281, p. 504.

21. Hoegy, W.R., Grebowsky, J.M., and Brace, L.H., Ionospheric Ion Composition from Satellite Measurements Made during 1970-1980: Altitude Profiles, Adv. Space Res., 1991, vol. 11, p. 173.

22. Seran, E., Frey, H.U., Fillingim, M., et al., Demeter High Resolution Observations of the Ionospheric Thermal Plasma Response to Magnetospheric Energy Input during the Magnetic Storm of November 2004, Ann. Geophys., 2007, vol. 25, p. 2503.

23. Horwitz, J., Brace, L., Comfort, R., and Chappell, C., Dual-Spacecraft Measurements of PlasmasphereIonosphere Coupling, J. Geophys. Res., 1986, vol. 91, p. 11203. 